\title{
Generation of Human Kidney Tubuloids from Tissue and Urine
}

\author{
Camilla Calandrini $^{1,2}$, Jarno Drost ${ }^{1,2}$ \\ ${ }^{1}$ Princess Máxima Center for Pediatric Oncology ${ }^{2}$ Oncode Institute
}

\section{Corresponding Author}

Jarno Drost

J.Drost@prinsesmaximacentrum.nl

\section{Citation}

Calandrini, C., Drost, J. Generation of Human Kidney Tubuloids from Tissue and Urine. J. Vis. Exp. (170), e62404, doi:10.3791/62404 (2021).

\section{Date Published}

April 16, 2021

DOI

$10.3791 / 62404$

URL

jove.com/video/62404

\section{Abstract}

Adult stem cell (ASC)-derived human kidney epithelial organoids, or tubuloids, can be established from healthy and diseased kidney epithelium with high efficiency. Normal kidney tubuloids recapitulate many aspects of their tissue of origin. They represent distinct nephron segments - most notably of the proximal tubule, loop of Henle, distal tubules, and collecting duct - and can be used to study normal kidney physiology. Furthermore, tubuloid technology facilitates disease modeling, e.g., for infectious diseases as well as for cancer. Obtaining kidney epithelial cells for tubuloid generation is, however, dependent on leftover surgical material (such as partial) nephrectomies) or needle biopsies. The ability to grow tubuloids from urine would provide an alternative, less invasive source of healthy kidney epithelial cells. It has been previously shown that tubuloid cultures can be successfully generated from only a few milliliters of freshly collected urine. This article describes the protocols to generate and propagate ASC-derived human kidney tubuloid cultures from tissue and urine samples.

\section{Introduction}

Kidneys perform the function of systemically controlling the balance of body fluids. The impairment of their physiological function can be caused by different factors, including diabetes, hypertension, and drug-induced toxicity ${ }^{1}$. For a better understanding of normal kidney physiology as well as the development of renal diseases, the use of representative preclinical models is crucial. In recent years, several in vitro kidney models have been generated based on the so-called organoid technology ${ }^{2}$. Organoids are three-dimensional, multicellular structures resembling the morphology and physiology of the tissue (normal or diseased) from which they originate. They can be generated from pluripotent (PSCs) or adult stem cells (ASCs), each with their own characteristics and applications.

PSC-derived kidney organoids mimic nephrogenesis $3,4,5$. They can also be established from patient-derived committed cells by forced dedifferentiation (induced pluripotency or iPSC). iPSCs can subsequently be differentiated into the different cell types of the nephron, the functional unit of the kidney, by timely exposure to specific growth factor 
cocktails. While creating a rather complete mini-organ in a dish, their establishment remains time-consuming, and due to the reprogramming protocol, iPSCs can be susceptible to undesired genetic instability ${ }^{6}$. Furthermore, iPSC organoids are not able to fully mature into adult kidney cells, revealing a transcriptome profile that resembles the fetal kidney at an early development stage ${ }^{7}$.

ASC-derived human kidney tubuloids have been shown to recapitulate the renewal of adult kidney epithelium. They primarily represent the proximal tubule, loop of Henle, distal tubules, and collecting duct, as confirmed by the expression of different transporter proteins ${ }^{8,9,10}$. The tubuloid culture protocol allows for the rapid expansion of patient-derived kidney tissue, while retaining a stable genome. Research applications include studying normal kidney physiology, nephrotoxicity, drug testing, as well as disease modelling $8,10,11,12$. A potential limitation of the establishment of patient-derived organoid cultures, including tubuloids, is the availability of fresh tissue. However, several reports have shown that urine can serve as a source for kidney epithelial cells, thereby providing a much simpler, less invasive strategy to obtain patient material for tubuloid cultures $^{8,13,14}$. Indeed, it has been recently shown that tubuloids can be grown from urine ${ }^{8}$. This article describes the establishment and maintenance of tubuloid cultures from kidney tissue and urine.

\section{Protocol}

NOTE: The experiments described herein were approved by the medical ethical committee of the Erasmus Medical Center (Rotterdam, the Netherlands) and Princess Máxima Center for Pediatric Oncology (Utrecht, the Netherlands).

\section{Generation of human kidney tubuloids from tissue}

1. Materials

1. Prewarm multiwell tissue culture plates $(6,12$ and 24 wells) overnight at $37^{\circ} \mathrm{C}$.

2. Prepare basal medium $(\mathrm{AdDF}+++)$ by adding 1x L-alanine/L-glutamine supplement, 1\% w/v 4(2-hydroxyethyl)-1-piperazine ethanesulfonic acid (HEPES, $10 \mathrm{mM}$ ), and 1\% Penicillin/Streptomycin antibiotics to Advanced DMEM/F12.

3. Prepare culture medium by adding $1.5 \% \quad$ B27 supplement, 10\% R-spondin-conditioned medium, epidermal growth factor (50 $\mathrm{ng} / \mathrm{mL})$, fibroblast growth factor-10 (100 ng/mL), N-acetylcysteine (1.25 mM), Rho-kinase inhibitor Y-27632 (10 $\mu \mathrm{M})$, broad-spectrum antibiotics $(0.1 \mathrm{mg} / \mathrm{mL})$, and A83-01 $(5 \mu \mathrm{M})$ to AdDF+++. Warm to $37^{\circ} \mathrm{C}$ before use.

4. Prepare the basement membrane extract (BME) by thawing an aliquot overnight at $4{ }^{\circ} \mathrm{C}$. Keep the BME on ice during the procedure.

5. Prepare collagenase solution by diluting collagenase to a final concentration of $1 \mathrm{mg} / \mathrm{mL}$ in AdDF+++, with the addition of $10 \mu \mathrm{M} Y-27632$. Warm up to $37^{\circ} \mathrm{C}$.

6. Prepare $10 \mathrm{~cm}$ Petri dishes, scalpels, and tweezers. Disinfect the utensils by applying an ultraviolet lamp for 20 min, followed by washings with disinfectant, demi water, and $70 \% \mathrm{v} / \mathrm{v}$ ethanol. Air-dry the utensils.

7. Prewarm a horizontal shaker to $37^{\circ} \mathrm{C}$. 
1. Collect kidney tissue in a $50 \mathrm{~mL}$ tube filled with $30-40$ $\mathrm{mL}$ of AdDF+++ medium. Place the piece of tissue in $\sim 1 \mathrm{~mL}$ of medium in a $10 \mathrm{~cm}$ Petri dish. Mince the tissue into pieces of $\sim 1 \mathrm{~mm}^{3}$ size using scalpels (Figure 1A).

2. Transfer the minced tissue to a $15 \mathrm{~mL}$ tube using forceps and scalpels. Add $5 \mathrm{~mL}$ of AdDF+++ to the Petri dish, wash, and collect the medium with a 10 $\mathrm{mL}$ sterile pipette. Transfer all these contents to the same tube.

3. Centrifuge at $300 \times g$ for $5 \mathrm{~min}$ at room temperature, and remove the supernatant. Add $3-4 \mathrm{~mL}$ of collagenase solution to the $15 \mathrm{~mL}$ tube. Move the tube to a horizontal shaker set at $37^{\circ} \mathrm{C}$ and a speed of $250 \mathrm{rpm}$.

4. After the first $15 \mathrm{~min}$ of incubation, check the sample and vigorously shake the tube. Repeat until the suspension is homogeneous and most pieces of tissue have disappeared, with a maximum incubation time of 45-60 min. (Figure 1B).

5. Fill up the tube with AdDF+++, and mix by inverting the tube $5-10 x$. Centrifuge at $300 \times g$ for $5 \mathrm{~min}$ at 4 ${ }^{\circ} \mathrm{C}$, and remove the supernatant. If the pellet is red, proceed with step 1.2.6. Otherwise, go to step 1.2.8.

6. Add $1 \mathrm{~mL}$ of red blood cell lysis buffer (see the Table of Materials) on top of the cell pellet. Gently tap the tube to resuspend the pellet (do not resuspend with pipette tip). Incubate at room temperature for $5 \mathrm{~min}$.

7. Fill up the tube with AdDF+++. Centrifuge at $300 \times$ $g$ for $5 \mathrm{~min}$ at $4{ }^{\circ} \mathrm{C}$, and remove the supernatant. If blood cells are still visible, repeat the procedure once more, starting from step 1.2.6. Otherwise, proceed with step 1.2.8.
8. If chunks of tissue are visible at this point of the protocol, proceed with step 1.2.8. Otherwise, proceed with the measurement of the pellet volume in step 1.2.9. Add $5 \mathrm{~mL}$ of AdDF+++ to the tube, and resuspend with a $10 \mathrm{~mL}$ sterile pipette. Filter the suspension through a $100 \mu \mathrm{m}$ nylon cell strainer placed on a $50 \mathrm{~mL}$ tube.

9. Transfer the filtered suspension to a new $15 \mathrm{~mL}$ tube. Centrifuge at $300 \times g$ for 5 min at $4{ }^{\circ} \mathrm{C}$, and remove the supernatant. Measure the volume of the cell pellet using a p1000 pipette set to a known volume. Carefully pipette up and down to resuspend without creating air bubbles. Transfer the tube to ice for $1 \mathrm{~min}$.

10. Add $70-75 \%$ volume of BME to the pellet. Resuspend using a p1000 or p200 pipette, and plate $15 \mu \mathrm{L}$ droplets in a prewarmed, multiwell cell culture plate $(6,12$, or 24 wells, based on total plating volume (<100 $\mu \mathrm{L}, 24$ wells; $100-200 \mu \mathrm{L}, 12$ wells; $>200 \mu \mathrm{L}, 6$ wells)).

11. Turn the plate upside down, and let the plate rest in the incubator for $15-20 \mathrm{~min}$ at $37^{\circ} \mathrm{C}$ (Figure 1C). Add prewarmed culture medium, and inspect the cultures (Figure 1C,D).

\section{Generation of human kidney tubuloids from urine}

NOTE: Urine is a hostile environment for cells. It is important for a successful execution of this protocol that urine samples are processed as soon as possible, preferably within $4 \mathrm{~h}$ from excretion. In the meantime, urine samples should be stored at $4{ }^{\circ} \mathrm{C}$.

\section{Materials}


1. Prewarm multiwell tissue culture plates $(6,12$ and 24 wells) overnight at $37^{\circ} \mathrm{C}$.

2. Prepare washing medium: AdDF+++ supplemented with broad-spectrum antibiotics $(0.1 \mathrm{mg} / \mathrm{mL})$ and 10 $\mu \mathrm{M}$ Y-27632.

3. Prepare culture medium as described above. Warm up at $37^{\circ} \mathrm{C}$ before use.

4. Prepare BME matrix. Keep on ice during the procedure.

2. Procedure

1. Collect a urine sample, and divide it equally into 50 $\mathrm{mL}$ tubes (Figure 2A-I). Add 10-20 mL of washing medium to each of the tubes. Centrifuge at $300 \times$ $g$ for $5 \mathrm{~min}$ at $4{ }^{\circ} \mathrm{C}$ (Figure 2A-II), and remove the supernatant carefully.

2. Add $10 \mathrm{~mL}$ of washing medium to each of the tubes. Carefully resuspend the pellets using a 10 $\mathrm{mL}$ sterile pipette. Centrifuge at $300 \times \mathrm{g}$ for $5 \mathrm{~min}$ at $4{ }^{\circ} \mathrm{C}$ (Figure 2A-III), and remove the supernatant carefully.

3. Resuspend the pellets, and transfer the contents of all the tubes into one $15 \mathrm{~mL}$ tube. Fill the tube with washing medium. Centrifuge at $300 \times \mathrm{g}$ for $5 \mathrm{~min}$ at $4{ }^{\circ} \mathrm{C}$ (Figure 2A-IV), and remove the supernatant.

4. Measure the volume of the cell pellet using a p1000 pipette set to a known volume. Carefully pipette up and down to resuspend without creating air bubbles. Transfer the tube to ice for $1 \mathrm{~min}$.

5. Add $70-75 \%$ volume of the BME to the pellet. Resuspend using a p1000 or p200 pipette, and plate $15 \mu \mathrm{L}$ droplets in a prewarmed, multiwell cell culture plate $(6,12$, or 24 wells, based on total plating volume $(<100 \mu \mathrm{L}, 24$ wells; $100-200 \mu \mathrm{L}, 12$ wells; $>200 \mu \mathrm{L}, 6$ wells)).

6. Turn the plates upside down in the incubator for $15-20$ min at $37^{\circ} \mathrm{C}$. Add prewarmed culture medium, and inspect the cultures (Figure 2B).

\section{Expansion of tubuloid cultures}

NOTE: Tubuloid cultures can be passaged approximately every 1-2 weeks with a split ratio of 1:2-1:3. They can be typically expanded for approximately 15 passages, with linespecific variations.

1. Materials

1. Prewarm multiwell tissue culture plates $(6,12$ and 24 wells) overnight at $37^{\circ} \mathrm{C}$.

2. Prepare basal medium (AdDF+++), and keep it on ice during the procedure.

3. Prepare culture medium as previously described. Warm up to $37^{\circ} \mathrm{C}$ before use.

4. Prepare BME matrix, and keep on ice during the procedure.

5. Prepare trypsin replacement agent with the addition of $\mathrm{Y}-27632$ to a concentration of $10 \mu \mathrm{M}$. Warm up to $37^{\circ} \mathrm{C}$ before use.

6. Autoclave non-filtered p10 tips.

7. Cool the centrifuge to $4{ }^{\circ} \mathrm{C}$.

2. Procedure

1. Disrupt the droplets containing the tubuloids by pipetting up and down with a p1000 pipette using the medium present in the well. Use the tip to scrape the bottom of the well, making sure to collect all cells attached to the bottom. 
2. Collect the contents in a $15 \mathrm{~mL}$ tube. Add $10 \mathrm{~mL}$ of AdDF+++. Centrifuge at $300 \times g$ for 5 min at $4{ }^{\circ} \mathrm{C}$, and remove the supernatant.

3. Based on the size of the pellet, add trypsin replacement agent supplemented with $10 \mu \mathrm{M}$ Y-27632. Use $1 \mathrm{~mL}$ of trypsin replacement agent for $200 \mu \mathrm{L}$ of BME droplets containing tubuloids. Incubate at $37^{\circ} \mathrm{C}$ for $5 \mathrm{~min}$.

4. Use a p1000 pipette with tip, and insert a nonfiltered, sterile p10 tip over the $1000 \mu \mathrm{L}$ tip. Pipette up and down for 20-30x to mechanically disrupt the organoids.

5. Check under the microscope to see if many intact organoids are still present in the tube (Figure 3A). If more than $10 \%$ of intact organoids are present at this point, repeat from the 5 min incubation in step 3.2.3 to the microscopic observation for intact organoids in step 3.2.5 once more. Otherwise, proceed with step 3.2.6.

6. Fill up the tube with AdDF+++. Centrifuge at $300 \times$ $\mathrm{g}$ for $5 \mathrm{~min}$ at $4{ }^{\circ} \mathrm{C}$, and remove the supernatant. Measure the volume of the cell pellet using a p1000 pipette set to a known volume. Carefully pipette up and down to resuspend without creating air bubbles. Transfer the tube to ice for $1 \mathrm{~min}$.

7. Add $70-75 \%$ volume of BME to the pellet. Resuspend using a p1000 or p200 pipette, and plate $15 \mu \mathrm{L}$ droplets in a prewarmed, multiwell cell culture plate $(6,12$, or 24 wells, based on total plating volume (<100 $\mu \mathrm{L}$, 24 wells; $100-200 \mu \mathrm{L}, 12$ wells; $>200 \mu \mathrm{L}, 6$ wells)).

8. Turn the plates upside down, and let the plate rest in the incubator for $15-20 \mathrm{~min}$ at $37^{\circ} \mathrm{C}$. Add prewarmed culture medium, and inspect the cultures (Figure 3B).

\section{Representative Results}

For kidney tissue, tubuloid structures typically appear within 7 days after establishment (Figure 1D). Lack of apparent growth within the first 7 days indicates an unsuccessful outcome of the protocol. Generally, tubuloid cultures need to be passaged within 1-2 weeks after first plating. For urine, cell growth becomes apparent approximately 14-21 days after establishment, with the appearance of compact tubuloid structures and/or adherent cells on the bottom of the plate (Figure 2B). Culture establishment most likely has failed if no growth can be detected with a brightfield microscope within 4 weeks after plating. For urine-derived cultures, the first passaging generally occurs between 3 and 4 weeks. While in the first passages kidney tubuloid cultures consist mainly of compact structures, the presence of cystic epithelial tubuloids increases with the increase of passage number (Figure 1D and Figure 2B). The successful generation of human kidney tubuloid cultures can be assessed by performing immunohistochemical staining for markers expressed in tubular kidney epithelium, such as paired box gene 8 protein (PAX8) (Figure 4A,B). 


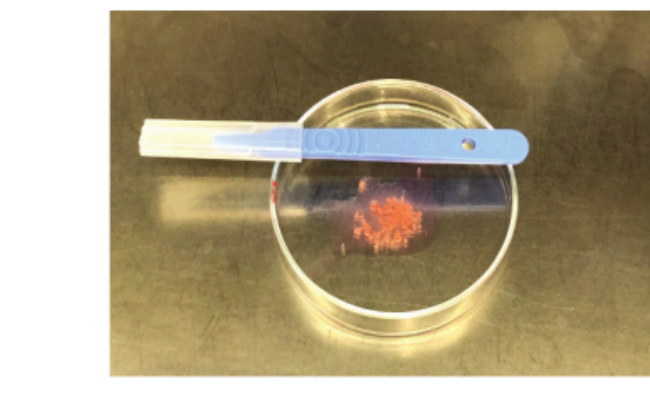

B

C
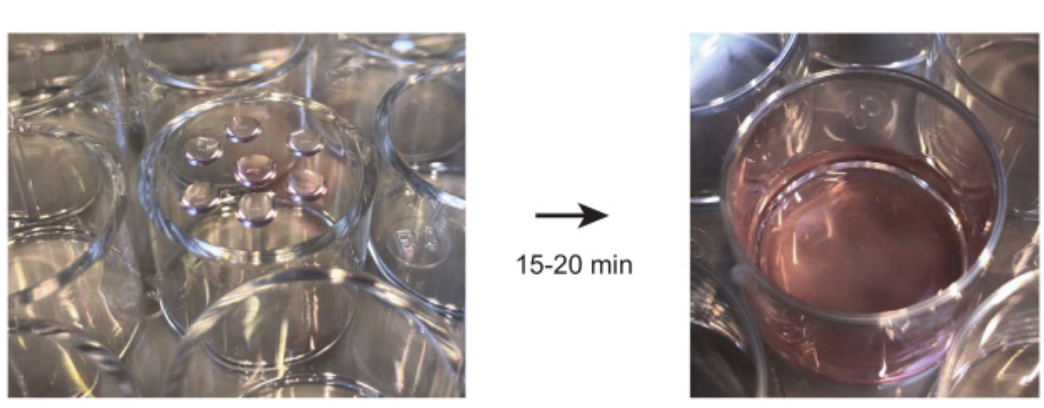

D
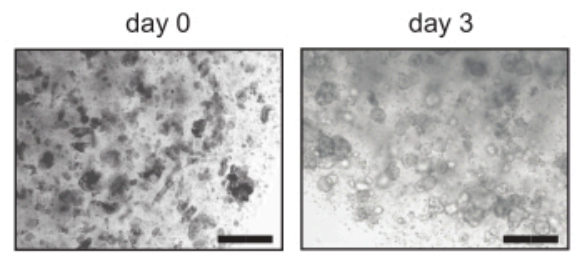

passage 0

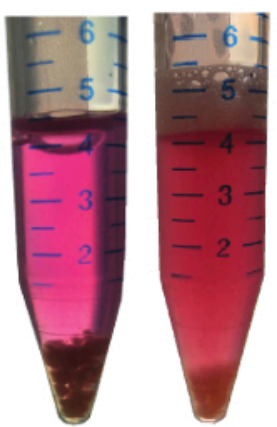

Digestion Digestion

$0 \mathrm{~min} \quad 45 \mathrm{~min}$

Figure 1: Tissue-derived kidney tubuloid cultures. (A) Overview of the procedure to mince kidney tissue. Tissue is minced to a size of $\sim 1 \mathrm{~mm}^{3}$ using scalpels. (B) Example of correct enzymatic digestion of healthy kidney tissue. Tissue is shown before (left) and after (right) 45 min of enzymatic digestion with collagenase. Few pieces of tissue are still visible at the bottom of the tube, and the solution should become cloudy, indicating the presence of cells in the suspension. (C) Representative image of cell culture plates after plating of BME droplets containing the processed kidney tissue. After plating the droplets, culture plates are turned upside down (left) and placed in the incubator at $37^{\circ} \mathrm{C}$. After $15-20$ min, prewarmed culture medium is added to the well (right). (D) Representative brightfield images of tissue-derived tubuloid cultures. The first tubuloid structures become visible 2-3 days after first seeding. With increasing passage numbers, tubuloids typically change morphology to a more cystic phenotype. Scale bars $=300 \mu \mathrm{m}$. Abbreviations: BME $=$ basement membrane extract. Please click here to view a larger version of this figure. 
A

I.

III.

IV.

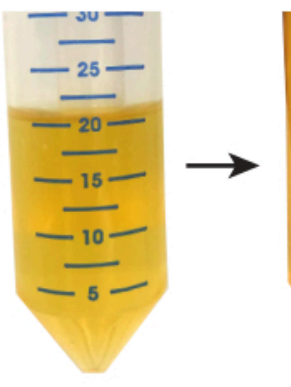

Sample collection

II.
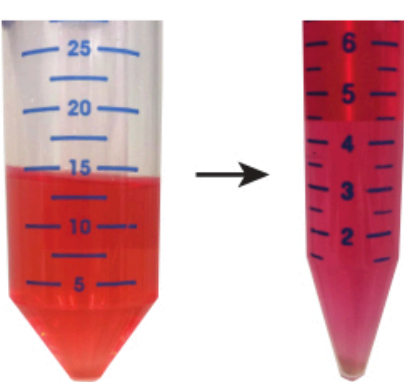

Second washing

B

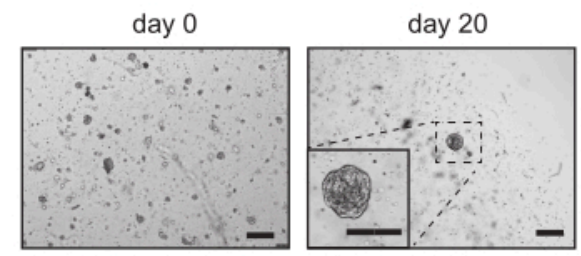

passage 0

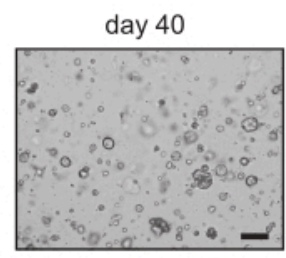

passage 4

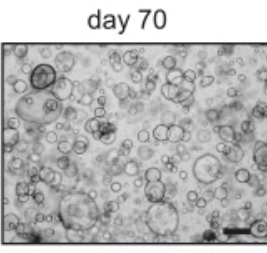

passage 7

Figure 2: Urine-derived kidney tubuloid cultures. (A) Overview of urine sample processing. As soon as possible after collection (I), urine samples are divided into $50 \mathrm{~mL}$ tubes and diluted in washing medium (II). After a second washing step (III), the content of the tubes is pooled and a third and final wash step (IV) is performed before plating. (B) Representative brightfield images of urine-derived tubuloid cultures. The first tubuloid structures and adherent cells should be visible within 21 days after first plating. Scale bars $=300 \mu \mathrm{m}$. Please click here to view a larger version of this figure. 
A

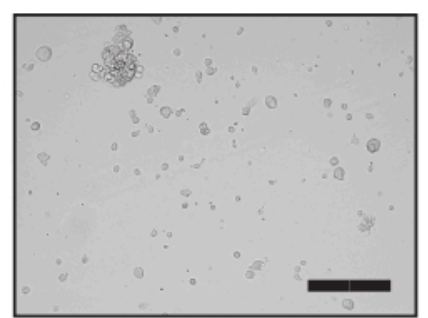

B

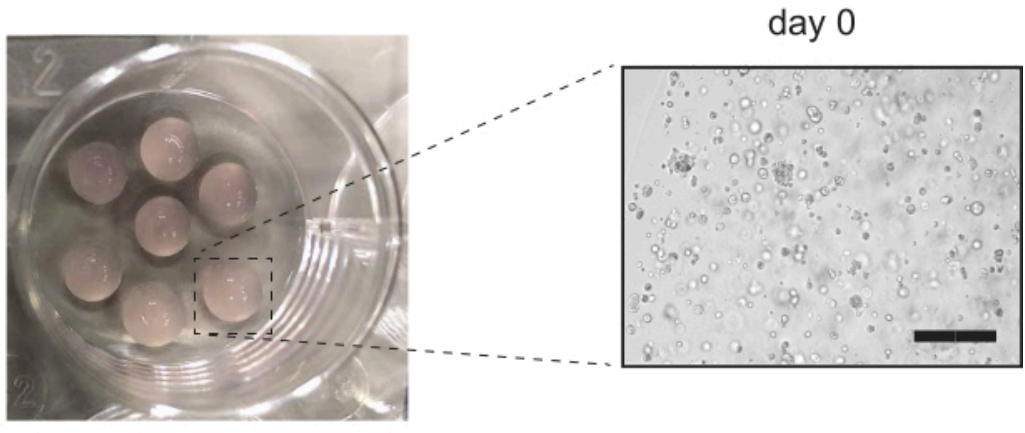

Figure 3: Passaging of kidney tubuloid cultures. (A) Representative image of kidney tubuloid cultures after enzymatic digestion. After completing digestion, no more than $10 \%$ of intact tubuloid structures should remain. Scale bar $=300 \mu \mathrm{m}$. $(\mathrm{B})$ Representative image of kidney tubuloid cultures after plating. Inspection of the cultures confirms that the majority of the tubuloids have been disrupted. Scale bar $=300 \mu \mathrm{m}$ Please click here to view a larger version of this figure. 
A

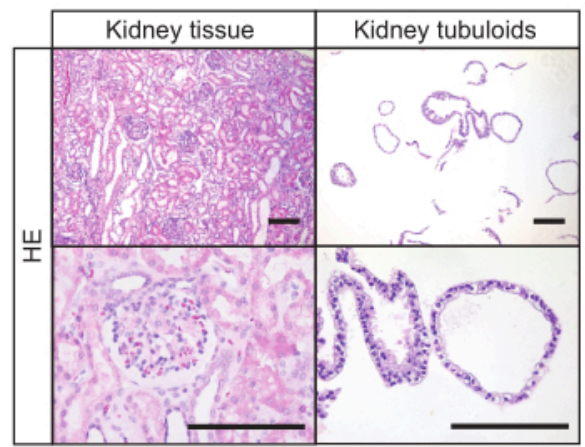

B

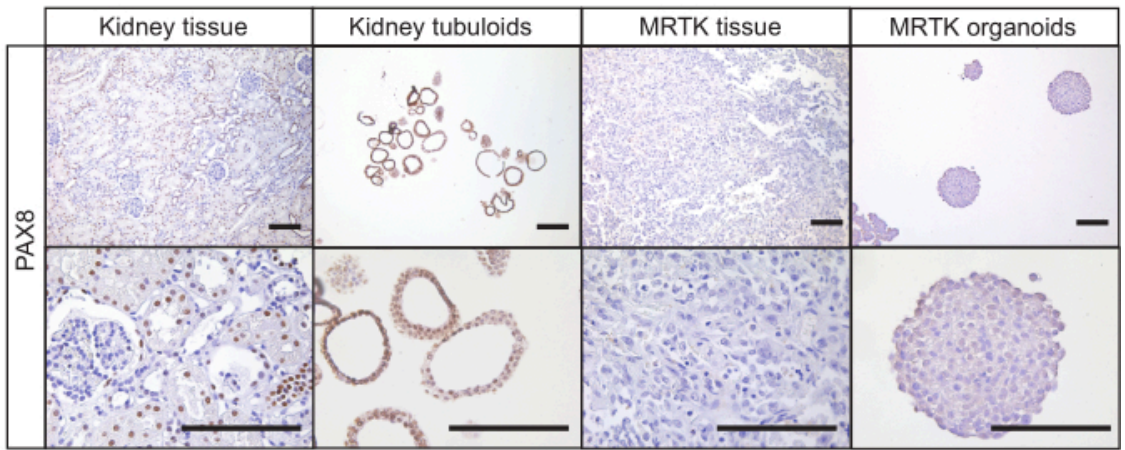

Figure 4: Histological characterization of tubuloid cultures. (A) H\&E staining of healthy kidney tissue and tubuloids. Scale bars = $100 \mu \mathrm{m}$. (B) Immunohistochemistry of PAX8 in normal kidney tissue, tubuloids, MRTK tissue, and MRTK organoids. PAX8 positivity of the organoid structures confirms their kidney epithelial origin. Healthy kidney tissue shows both positive (tubules) and negative structures (glomeruli). MRTK tissue and organoids were included as negative control. Scale bars $=100 \mu \mathrm{m}$. Abbreviations: H\&E = hematoxylin and eosin; PAX8 = paired box gene 8; MRTK = malignant rhabdoid tumor of the kidney. Please click here to view a larger version of this figure.

\section{Discussion}

Organoids are considered avatars of the tissue from which they are derived. They allow for rapid expansion of patient material while retaining the genotypic and phenotypic characteristics of the tissue of origin ${ }^{15}$. Organoid technology has recently opened the doors for the development of more representative preclinical models, which can be used as important tools to translate findings from the bench to the bedside. Kidney tubuloids are promising in vitro models for testing drug-induced nephrotoxicity, a common side effect of many chemotherapeutic drugs $2,8,12$. As such, patientderived tumor organoid cultures were demonstrated to be predictive for patient response to treatment ${ }^{16,17,18}$. Testing drugs in a high-throughput manner on tubuloids therefore potentially allows better definition of therapeutic windows and decreases the risk of drug-induced nephrotoxicity in patients. 
Commonly used antibiotics have been described to exert a toxic effect on the kidneys ${ }^{19}$. Although the presence of broad-spectrum antibiotics is necessary for the successful establishment of the cultures by preventing contamination, it is important to consider their potential nephrotoxicity. Although no negative effects of antibiotics have been observed on the establishment of tubuloid cultures, further investigation is needed to thoroughly evaluate their effects. Tubuloids can be exploited for studying and modeling diseases ${ }^{8}$. Ciliopathies (pathological dysfunction of cilia) as well as other genetic syndromes affecting the kidney could be studied by either generating tubuloid lines directly from affected subjects, or by using healthy cultures in which disease-specific driver mutations can be introduced via CRISPR/Cas9 genome editing ${ }^{20}$.

Although tubuloids are multicellular kidney cultures, they lack several renal cell types, including podocytes and endothelial cells $^{8}$. Moreover, in contrast to some other ASC-derived organoid models, tubuloids have a limited replicative potential as they can be cultured for approximately 15 passages. This limited lifespan can, however, be significantly extended by the addition of Wnt to the culture medium ${ }^{21}$. Further optimization of the tubuloid culture protocol is required to make them even more representative of the kidney, including more differentiated cell types. Although the efficiency of tubuloid establishment from tissue samples is very high (>95\%), it can, in rare cases, fail. There can be different causes including: 1) poor quality of the starting material (e.g., necrotic tissue as a consequence of drug treatment), 2) overdigestion of the tissue sample, or 3) contamination of the primary sample.

To make sure that the quality of the tissue samples received is sufficient to proceed with the protocol, it is important to maintain close contact with the pathology staff performing the evaluation of the tissue upon surgery. If sufficient material is available, its viability must be confirmed by histological examination (e.g., hematoxylin and eosin staining). Furthermore, to prevent cell lysis during enzymatic digestion, it is important that the incubation procedure is no longer than $1 \mathrm{~h}$. Lastly, to prevent contamination, antibiotics and antifungal agents should be added to the washing and culture media.

Urine can contain exfoliated epithelial cells that are not derived from the kidney ${ }^{22}$, which can contaminate the tubuloid cultures. These include, for instance, urothelium cells that are, in contrast to renal tubular cells, positive for tumor protein $\mathrm{P} 63$ and negative for $\mathrm{PAX} 8^{8}$. It is therefore recommended to test the cultures for PAX8 positivity to confirm the purity of established kidney tubuloid lines before proceeding with follow-up experiments (Figure 4B).

Urine represents a hostile environment for cells due to high osmotic pressure and low $\mathrm{pH}$. It is therefore crucial for the success of the protocol that samples are processed as soon as possible upon urine collection. As such, the collected urine should be diluted and extensively washed with buffered solution as soon as possible to ensure presence of viable cells at the time of seeding. The success rate of tubuloid establishment will significantly decrease if urine is stored for several hours before processing. Lastly, although sterile, urine has a high risk of contamination associated with the collection process. It is therefore important to supplement washing and growth medium with antibiotics and antifungal agents. When taking all the above into account, a success rate of approximately $50 \%$ can be achieved.

\section{Disclosures}

The authors declare no conflict of interest. 


\section{Acknowledgments}

We thank all the patients and their families for participating in the study. We thank the clinical team who facilitated our research. We are grateful for support of the European Research Council (ERC) starting grant 850571 (J.D.), the Dutch Cancer Society (KWF)/Alpe d'HuZes Bas Mulder Award (no. 10218, J.D.), Oncode Institute, and Foundation Children Cancer Free (KiKa no. 292, C.C.)

\section{References}

1. Romagnani, P. et al. Chronic kidney disease. Nature Reviews. Disease Primers. 3, 17088 (2017).

2. Ooms, A. H., Calandrini, C., de Krijger, R. R., Drost, J. Organoid models of childhood kidney tumours. Nature Reviews. Urology. 17 (6), 311-313 (2020).

3. Takasato, M. et al. Kidney organoids from human iPS cells contain multiple lineages and model human nephrogenesis. Nature. 526 (7574), 564-568 (2015).

4. Low, J. H. et al. Generation of human PSC-derived kidney organoids with patterned nephron segments and a de novo vascular network. Cell Stem Cell. 25 (3), 373-387.e9 (2019).

5. Little, M. H., Combes, A. N. Kidney organoids: accurate models or fortunate accidents. Genes \& Development. 33 (19-20), 1319-1345 (2019).

6. Papapetrou, E. P. Patient-derived induced pluripotent stem cells in cancer research and precision oncology. Nature Medicine. 22 (12), 1392-1401 (2016).

7. $\mathrm{Wu}, \mathrm{H}$. et al. Comparative analysis and refinement of human PSC-derived kidney organoid differentiation with single-cell transcriptomics. Cell Stem Cell. 23 (6), 869-881.e8 (2018).
8. Schutgens, F. et al. Tubuloids derived from human adult kidney and urine for personalized disease modeling. Nature Biotechnology. 37 (3), 303-313 (2019).

9. Jun, D. Y. et al. Tubular organotypic culture model of human kidney. PLoS One. 13 (10), e0206447 (2018).

10. Grassi, L. et al. Organoids as a new model for improving regenerative medicine and cancer personalized therapy in renal diseases. Cell Death \& Disease. 10 (3), 1-15 (2019).

11. Yousef Yengej, F. A., Jansen, J., Rookmaaker, M. B., Verhaar, M. C., Clevers, H. Kidney organoids and tubuloids. Cells. 9 (6), 1326 (2020).

12. Calandrini, C. et al. An organoid biobank for childhood kidney cancers that captures disease and tissue heterogeneity. Nature Communications. 11 (1), 1310 (2020).

13. Jansen, J. et al. A morphological and functional comparison of proximal tubule cell lines established from human urine and kidney tissue. Experimental Cell Research. 323 (1), 87-99 (2014).

14. Zhou, T. et al. Generation of human induced pluripotent stem cells from urine samples. Nature Protocols. 7 (12), 2080 (2012).

15. Drost, J., Clevers, H. Organoids in cancer research. Nature Reviews Cancer. 18 (7), 407-418 (2018).

16. Vlachogiannis, G. et al. Patient-derived organoids model treatment response of metastatic gastrointestinal cancers. Science. 359 (6378), 920-926 (2018).

17. Ooft, S. N. et al. Patient-derived organoids can predict response to chemotherapy in metastatic colorectal cancer patients. Science Translational Medicine. 11 (513), eaay2574 (2019). 
18. Tiriac, $H$. et al. Organoid profiling identifies common responders to chemotherapy in pancreatic cancer. Cancer Discovery. 8 (9), 1112-1129 (2018).

19. Morales-Alvarez, M. C. Nephrotoxicity of antimicrobials and antibiotics. Advances in Chronic Kidney Disease. 27 (1), 31-37 (2020).

20. Drost, J. et al. Sequential cancer mutations in cultured human intestinal stem cells. Nature. 521 (7550), 43-47 (2015).

21. Miao, Y. et al. Next-generation surrogate Wnts support organoid growth and deconvolute Frizzled pleiotropy in vivo. Cell Stem Cell. 27 (5), 840-851.e6 (2020).

22. Dörrenhaus, A. et al. Cultures of exfoliated epithelial cells from different locations of the human urinary tract and the renal tubular system. Archives of Toxicology. 74 (10), 618-626 (2000). 